\title{
Application of a moments spray model to solid cone diesel sprays
}

Link to publication record in Manchester Research Explorer

\section{Citation for published version (APA):}

Emekwuru, NG., \& Watkins, P. (2011). Application of a moments spray model to solid cone diesel sprays. In Application of a moments spray model to solid cone diesel sprays

\section{Published in:}

Application of a moments spray model to solid cone diesel sprays

\section{Citing this paper}

Please note that where the full-text provided on Manchester Research Explorer is the Author Accepted Manuscript or Proof version this may differ from the final Published version. If citing, it is advised that you check and use the publisher's definitive version.

\section{General rights}

Copyright and moral rights for the publications made accessible in the Research Explorer are retained by the authors and/or other copyright owners and it is a condition of accessing publications that users recognise and abide by the legal requirements associated with these rights.

\section{Takedown policy}

If you believe that this document breaches copyright please refer to the University of Manchester's Takedown Procedures [http://man.ac.uk/04Y6Bo] or contact uml.scholarlycommunications@manchester.ac.uk providing relevant details, so we can investigate your claim.

\section{OPEN ACCESS}




\title{
APPLICATION OF A MOMENTS SPRAY MODEL TO SOLID CONE DIESEL SPRAYS
}

\author{
Nwabueze G. Emekwuru \\ Midlands Simulation Group, School of Technology, University of Wolverhampton, United Kingdom.
}

A. Paul Watkins

School of Mechanical, Aerospace, and Civil Engineering, University of Manchester, United Kingdom.

Copyright @ 2011 Society of Automotive Engineers of Japan, Inc.

\begin{abstract}
Discrete droplet models in which parcels of droplets are tracked in space in a Lagrangian framework have historically dominated the modelling of fuel sprays. These models are computationally expensive, as the chaotic motions of each droplet have to be predicted. A development of a spray model that captures the full polydisperse nature of spray flow without using droplet size classes has been presented in previous publications. In this paper, the model is applied to solid cone diesel sprays. The size information concerning the spray is obtained by calculating three moments of the droplet-size distribution function from transport equations and one moment from a Gamma size distribution function. The predictions from the model are compared with results from experiments, a discrete droplet model, and two moments-based models. These indicate that droplet break-up, collisions, penetration and sizes are successfully modelled.
\end{abstract}

\section{INTRODUCTION}

As concerns about the environmental effects of the use of fuel sprays increase, the need to better understand the fuel spray processes and, hence, increase their efficiency has intensified. Advances in the optical measurement techniques used for observing fuel sprays and the computational capacity of computers have enabled better understanding of fuel spray structures and more rigorous validation of fuel spray models. Many computational fuel spray models are based on the discrete droplet model (DDM), pioneered by Dukowicz [1]. With this model the equations of motion for a turbulent carrier gas are solved in an Eulerian scheme, while Lagrangian equations of motion for the liquid droplets are solved along true path lines. Source terms in the transport equations are used to link the two calculation schemes and hence the two phases. This mixed Eulerian-Lagrangian approach has been shown to efficiently model the liquid phase into groups of identical droplets and the dispersed liquid phase can be more naturally written in a Lagrangian manner. The DDM method has the disadvantage of being computationally intensive, as the chaotic motions of the individual droplets have to be predicted in order to present the complete nature of the spray [2][3]. Researchers have tried to tackle this problem with several approaches, including using an Eulerian-Eulerian approach [4]. Using an Eulerian treatment for the liquid phase involves using a number of grid points in the flow at which solutions of dependent variables are required that can be fewer than the number of droplets that have to be tracked in a Lagrangian treatment, thus it is potentially more computationally efficient [5]. However, the models used so far for the Eulerian-Eulerian approach have followed similar methods used in the DDM approaches by considering size groups as complete separate phases, leading to schemes involving many phases and, thus, computationally intensive [4].

An alternative Eulerian-Eulerian fuel spray method has been presented which employs the first four moments of the droplet-size distribution to describe the distribution of the droplet sizes [6][7]. This model is more computationally efficient compared to the previously mentioned Eulerian-Eulerian and DDM models because size groups are not considered, an Eulerian treatment is used for the liquid phase, and the need to solve thousands of Lagrangian equations of motion for the droplet parcels is eliminated [6]. In this model, only the last two moments of the number distribution function are calculated using transport equations, the first two are approximated from a presumed droplet number size distribution, thus introducing much complexity into the solution scheme and the development of the sub-models. An attempt has been made to evaluate the first four moments of the distribution from the transport equations but the droplet break up and collision models could not be included [8][22] due to associated numerical issues. 
Details of a new model that predicts the last three moments of the number distribution function from transport equations have been presented [9][10]. This reduces the complexity inherent in the Beck and Watkins model [6][7] because the need to presume a distribution function for the droplet sizes has been reduced. However, three areas (the inlet, drag model, droplet break up/collision) still require such a distribution and a general Gamma distribution function has been used. Finally, the first moment is evaluated from this distribution function, thus, eliminating the need for a fourth transport equation. This improves the numerical stability of the model. Previous publications have described the capability of the model to accurately predict the characteristics of water sprays [9][11]. In this paper, the application of this model to solid-cone diesel sprays is presented. As the detailed derivation of the equations for the model has been presented before [9][10], only a brief description of the mathematical modelling pertinent to diesel spray application is presented in the next section. The results section presents the capabilities of the new model, noting how it compares with experimental data and other fuel spray models. Conclusions and suggestions for improving the model are presented in the last section.

\section{MATHEMATICAL MODELLING}

\section{DROPLET SIZE DISTRIBUTION}

The accurate representation of the range of droplets sizes is crucial in the modeling of polydisperse sprays. The Rosin-Rammler expression [12] for the droplet size distribution is widely used by researchers [13]. In this study, three areas require a size distribution; the inlet, drag model, and the droplet break up/collision. A general Gamma distribution has been used in these areas, and is given by

$$
n(r)=\frac{\alpha^{k}}{\Gamma(k) r_{32}^{k}} r^{k-1} e^{-\alpha\left(\frac{r}{r_{32}}\right)}
$$

where $r_{32}$ is the Sauter mean radius and $\Gamma(k)$ is the Gamma function defined by the integral

$$
\Gamma(k)=\int_{0}^{\infty} e^{-x} x^{k-1} d x
$$

The two parameters defining the functional form are $r_{32}$ and $k$.

The functional forms of equation (1) for various values of $k$ are shown in figure (1).

From figure (1), clearly a variety of uni-modal distributions can be obtained, ranging from relatively skewed examples when $k$ is small, to symmetric examples for large values of $k$.

\section{MOMENT TRANSPORT EQUATIONS}

The novelty of the moments spray model is that droplet parcels are not considered like in DDM spray models; instead, moments of the droplet-size distribution are used to describe the distribution of the droplet sizes. The first four moments of the droplet number probability distribution, $Q_{0}$ to $Q_{3}$, are used in the model [6][9]. $Q_{0}$ is the total number of droplets, $Q_{1}$ is the total sum of radii of the droplets, $4 \pi Q_{2}$ is the total surface area of the droplets and $\frac{4 \pi Q_{3}}{3}$ is the total volume of the droplets, all per unit total volume. In the 'two-moments' model [6][7][13], the last two moments are calculated from transport equations, while the first two moments, $Q_{0}$ and $Q_{1}$, are calculated by assuming a representative size distribution for the sprays, which is truncated to match the local Sauter mean radius of the spray. This added some complexity to the modeling. In the present study, a 'three-moments' scheme [9] is used and $Q_{1}, Q_{2}$, and $Q_{3}$ are calculated by solving transport equations for both the moments and the appropriate moment-averaged convection velocities. The droplet number, $Q_{0}$, is simply evaluated from the Gamma distribution [9] by partial integration of the moments of equation (1), as

$$
Q_{0}=\frac{(k+2)}{k r_{32}} Q_{1}
$$

Thus, a fourth transport equation (for $Q_{0}$ ) is not needed, and a presumed distribution function for the droplet number $\left(Q_{1}\right)$ is eliminated. This improves the numerical stability of the model [9].

In the moments model the set of moment transport equations $(i=1,2,3)$ can be concisely represented by:

$$
\frac{\partial Q_{i}}{\partial t}+\frac{\partial}{\partial x_{j}}\left(Q_{i} U_{l i j}\right)=-S_{Q_{i}}
$$

The respective liquid-phase momentum equations can also be written concisely as:

$$
\begin{aligned}
& \frac{\partial}{\partial t}\left(Q_{i} U_{l i j}\right)+\frac{\partial}{\partial x_{k}}\left(Q_{i} U_{l i j} U_{l i k}\right)+U_{l 3 j} B_{Q_{i}}+ \\
& U_{l i j}\left(S_{Q_{i}}-B_{Q_{i}}\right)=\frac{\partial}{\partial x_{k}}\left(Q_{i} \sigma_{v} v_{l} \frac{\partial U_{l i j}}{\partial x_{k}}\right)-S_{U_{l i j}}
\end{aligned}
$$

The source terms $S_{Q i}$ represent the effects on the moments of droplet break-up, droplet collisions and evaporation. The term $B_{Q i}$ represents the break-up part of $S_{Q i}$. The source terms $S_{\text {Ulij }}$ describe the effects of drag on the droplet momentum. A complete description of the source terms can be found in reference [9]. 
The carrier gas is considered to be turbulent, and the turbulence modelled by the $k-\varepsilon$ model of Launder and Spalding [14].

\section{DISCRETIZATION}

The spray test cases considered are axisymmetric. The transport equations are discretized in a finite volume framework [15]. A hybrid central/upwind is used for the spatial differencing, while an Euler implicit method is used for the temporal differencing. Details of the algorithm used have been presented in Emekwuru \& Watkins [9].

\section{PARAMETRIC TESTS}

High-pressure narrow angle sprays are such as found in diesel injection systems. The very high-pressure values in these cases, which are not available in the experiments [11] used for validating the 'three-moments' model for water spray modeling, allow a closer assessment of the momentum transfer model through spray penetration results. The high-pressure cases also result in high droplet collisions due to the relatively dense spray and high levels of secondary droplet break up, thus the collision and droplet break up models are further validated.

The experiments of Hiroyasu and Kadota [16] are used. In the experiments, diesel fuel is injected into high-pressure, room-temperature gaseous environments using a diesel injection system. The penetration data were measured photographically. The Sauter mean diameter of droplets were measured using the liquid immersion sampling technique with the results given at a distance of $65 \mathrm{~mm}$ downstream from the nozzle. The test conditions are given in Table (1). The injection pressure values are nearly $10^{2}$ times higher than the values in the experiments presented in [11], while the ambient pressure values are up to 50 times more. These experiments have been modelled by many scholars including Reitz and Diwakar [17] using a DDM scheme, Beck and Watkins [18] using a 'two-moments' scheme and, finally, Yue and Watkins [8] (with the details in [22]) using a 'four-moment' scheme and these provide a useful comparison for the 'three-moments' scheme used in this study. The Reitz and Diwakar [17] model assumes that atomization and droplet break up are indistinguishable processes within the dense spray at the nozzle exit, therefore atomization is determined by injecting droplets, called 'blobs', that are of the same size as the nozzle exit diameter. The model then accounts for droplet break up, droplet collision and coalescence, and the effect of droplets on the gas turbulence. The other models [18][22] have already been described in the previous sections. The computational grid used is presented in figure (2).

For brevity, some of the results of the parametric tests are presented here; the complete results are presented in [10]. Figure (3) shows the variation of the spray penetration with ambient pressure. As expected, the model predicts that penetration of the spray falls with increases in ambient pressure.
Increases in pressure of the carrier gas results in greater gas density, thus the liquid droplets experience a greater resistance to motion resulting in lower penetration. The predicted Sauter mean diameter values of the droplets increase with increased axial distances from the nozzle as droplet coalescence dominates over droplet break up at these distances [10] (see also figure (4)). The model also predicts the presence of larger droplet sizes with increases in ambient pressure (see also figures (8) to (10), and the next section). As the ambient pressure is increased, the possibility of droplet collision is increased as less spray penetration leads to more droplets catching up and colliding with previously injected droplets. Thus, the model correctly predicts that the changes in droplet size are not only due to droplet break up and collision. Similar results were obtained for the 'two-moments' model [18].

Figure (4) presents the line and cloud contours of the sauter mean diameter (A) and axial droplet velocity (B) of the computational spray. The figure shows that near the injector nozzle, the droplet velocity is high and the droplet sizes are small due to droplet break up from the high droplet momentum. The center of the spray contains smaller droplets, as they are entrained more readily into the spray center because they experience more drag. But further down the spray, larger droplet sizes are observed as the larger drops travel further, compared to smaller droplets, because they experience less drag. Also, because the droplet velocity decreases towards the spray head, droplet collisions and coalescence increase and these lead to larger sized droplets. The predicted spray shapes and contours are physically reasonable.

\section{COMPARISON WITH EXPERIMENTS}

The parameters used for the 'three-moments' (3M) model are presented in Table (2). The exact data from experimental values in [16], wherever possible, are used in the model. The parameters for the numerical calculations from Beck and Watkins [18], and Yue [22] are presented in Table (3).

\section{RESULTS AND DISCUSSION}

The results from the $3 \mathrm{M}$ model, the DDM model from Reitz and Diwakar [17], Beck and Watkins [18], and Yue [22] against the experimental work of Hiroyasu and Kadota [16] are presented next. The penetration comparisons for the $1.1 \mathrm{MPa}$ ambient pressure cases are presented in figure (5). It is seen that the 'two-moments' model from [18] matches the experimental data excellently. The DDM model from Reitz and Diwakar [17] matches the profile excellently but over predicts the spray penetration slightly throughout the profile. This is attributed to the lack of a precise definition of spray penetration in both computations (from [17]) and experiments (from [16]). The definition of penetration used by [18] is from Brandstätter et al [19] in which this is determined as the point behind which $99 \%$ of the spray mass is located. Yue [22] gives no definition for spray penetration. For the present study penetration is defined as the value of the furthest axial distance 
along the spray centerline in which there is any volume of liquid present; this is given by the presence of a local value for $Q_{0}$. The model in [22] under predicts the spray penetration further downstream with the reverse situation nearer the nozzle. The $3 \mathrm{M}$ model shows a similar trend but with closer results compared to the experimental data. Yue [22] believes that the trend in the 'four-moment' model is due to the lack of the droplet collision and break up sub-models in the model; therefore there is a lack of droplet break up near the nozzle leading to large droplets traveling too fast and the reverse further downstream due to lack of droplet collision. However, the authors suggest that the reasons for the trend can also be partly attributed to the drag sub model. For instance, Stekol"shchikov et al [20] showed that even within a certain range of Weber number, the drag coefficient of a drop can vary remarkably. There is also a suggestion by Kuo and Bracco [21] that pulsed injections (as used in the experiments by Hiroyasu and Kadota [16]) could give different variations of spray penetration/droplet size values compared to steady spray injections (as assumed by the spray models).

This trend continues for the $3.0 \mathrm{MPa}$ atmospheric pressure case (figure (6)) with the models from [18] and [17] predicting higher penetration but matching the penetration profile shape excellently while the $3 \mathrm{M}$ model and that from [22] over predict the penetration nearer the nozzle and under predict the penetration further downstream.

For the 5.0 MPa cases the trend is still evident even though, apart from the Yue model [22], the predicted results from the models are satisfactory; Figure (7).

The corresponding Sauter mean radius (SMR) values for the experiments are presented next. The SMR values are presented for only downstream distances from $40 \mathrm{~mm}$ to $80 \mathrm{~mm}$ mainly because experimental data from Hiroyasu and Kadota [16] are given for only $65 \mathrm{~mm}$ from the injector and also because the injection conditions for the Reitz and Diwakar [17] model are treated differently from the moment distribution models. From figures (8) to (10), it is seen that all the models correctly predict the increase in droplet sizes with increasing ambient pressure values. The models also show smaller droplet sizes nearer the nozzle and a gradual increase further downstream. This is as expected as it reflects the dominance of droplet break up nearer the nozzle and a gradual predominance of droplet collision further downstream.

From the 1.1 MPa ambient pressure case (figure (8)), the 3M model and the DDM model from Reitz and Diwakar [17] predict greater droplet break up nearer the nozzle and hence smaller droplet sizes at this region compared to the model from Beck and Watkins [18], but further downstream, the 3M model shows a higher droplet coalescence resulting in higher droplet sizes compared to the Beck and Watkins [18] and the Reitz and Diwakar [17] models. Experimental data, at $65 \mathrm{~mm}$ axial distance from the nozzle, is matched by the 3M model and the Beck and Watkins [18] models, while the DDM and the Yue [22] models under predict the values. Yue [22] attributed this to a lack of droplet break up and collision sub-models in the model.

The same trend is observed in the $3.0 \mathrm{MPa}$ ambient pressure case (figure 9), though all the models except that from [22] show a similar profile with the $3 \mathrm{M}$ model predicting the closest SMR values to the experimental data. No data beyond $50 \mathrm{~mm}$ from the nozzle are presented for the model in [22] due to numerical instabilities experienced with the model.

Finally, with the $5.0 \mathrm{MPa}$ case (figure 10), the pattern continues, though in this case, again the $3 \mathrm{M}$ model matches the experimental data excellently while the DDM model from Reitz and Diwakar [17] over predicts the droplet sizes. It is suggested that this is due to the effect of the pulsed injections/steady injections observation by Kuo and Bracco [21] but it might be that since the model collected data at $10 \mathrm{~ms}$ (compared to up to $20 / 25 \mathrm{~ms}$ for the moment based models [18][22]), it might just have been insufficient time for steady state droplet size values to be collected for the higher pressure cases, thus the presence of higher droplet sizes. The model from [22] offers no results at $65 \mathrm{~mm}$ downstream of the nozzle due to numerical instabilities experienced with the model.

These cases confirm that the break up and collision models are behaving well qualitatively. The very good prediction of the droplet sizes at various atomizing air pressures and ambient pressures also confirm that both models are performing quantitatively well. Also, the droplet parameters used in the droplet collision modeling are seen to be appropriate.

\section{CONCLUSION}

The application of a spray model that captures the full polydisperse nature of spray flow without using droplet size classes, to solid cone diesel sprays has been presented in this paper. The size information concerning the spray is obtained by calculating three moments of the droplet-size distribution function from transport equations and one moment from a Gamma size distribution function. The main novelty of this spray model is that droplet size classes are not considered, unlike in the DDM schemes where the chaotic motions of the droplets have to be tracked and predicted. The DDM schemes can become computationally expensive due to the large number of droplets required to achieve statistical convergence [3].

The 'three-moments' model has been successfully applied to water sprays [9][11]. However, high-pressure solid cone diesel injection cases present a closer assessment of the momentum transfer capabilities of the model which was not possible in [9][11]. Predictions from the model are compared with experimental data [16], and numerical data from a DDM spray model and two 'moments' spray models. 
Predicted results from the model for the experimental spray penetration values indicate that these are under predicted upstream and over predicted downstream the injector nozzle, even though the overall spray penetration profile is predicted. The deviations from the experimental results reduce with the higher injection cases. The results compare well the Yue [22] model but the other models [17][18] predict less deviation from the experimental penetration data. While the momentum transfer capabilities of the model is satisfactory, it may be necessary to perform experimental studies for particular cases to derive the particular drag model applicable, or explore other droplet drag models.

The predicted results from the model for the SMR values from the experiments indicate that the model correctly predicts increases in droplet sizes with increasing ambient pressure values. The other models [17][18][22] also correctly predict this trend. In all the cases presented, the present 'three-moments' model matches the experimental data for the SMR excellently and compares well with the results from the other models [17][18][22]. Thus, the droplet breakup and collision models used in the 'three-moment' model [9] are applicable to high-pressure diesel injection sprays.

Overall, the results indicate that the 'three-moments' spray model is applicable to high pressure, solid cone, diesel sprays and also compare well with DDM and other 'moment' spray models.

\section{NOMENCLATURE}

$\begin{array}{ll}\mathrm{B}_{\mathrm{Qi}} & \text { Source Term due to Breakup } \\ \mathrm{e} & \text { Coefficient of restitution } \\ \mathrm{k} & \text { Unit vector } \\ \mathrm{k} & \text { Thermal Conductivity, } \mathrm{Wm}^{-1} \mathrm{~K}^{-1} \\ \mathrm{n}(\mathrm{r}) & \text { Turbulent Kinetic Energy, } \mathrm{Jkg}^{-1} \\ \mathrm{Q} & \text { Droplet Moment } \\ \mathrm{Q}_{0} & \text { Total Number } \\ \mathrm{Q}_{1} & \text { Sum of Radii, } \mathrm{m} \\ \mathrm{Q}_{2} & \text { Sum of Squares of Radii, } \mathrm{m}^{2} \\ \mathrm{Q}_{3} & \text { Sum of Cubes of Radii, } \mathrm{m}^{3} \\ \mathrm{r} & \text { Radius, } \mathrm{m} \\ \mathrm{S} & \text { Source Term } \\ \mathrm{t} & \text { Time, } \mathrm{s} \\ \mathrm{U} & \text { Velocity, } \mathrm{m} / \mathrm{s}\end{array}$

\section{Acronyms}

DDM Discrete Droplet Model

SMD Sauter Mean Diameter

SMR Sauter Mean Radius

\section{Greek Symbols}

$\alpha \quad$ Non-dimensional size parameter

$\varepsilon \quad$ Dissipation Rate, $\mathrm{m}^{2} \mathrm{~s}^{-3}$

\section{REFERENCES}

1. J. K. Dukowicz, A particle-fluid numerical model for liquid sprays. J. Computational Physics, 35(2), pp. 229-233, 1980.

2. A. D. Gosman, \& E. loannides, Aspects of computer simulation of liquid fuelled combustors. Technical Paper 81-0323. AIAA Press, Washington, DC, 1981.

3. M. R. Archambault, Stochastic Spray Flow Models: A Review, ILASS-Americas 22nd Annual Conference on Liquid Atomization and Spray systems, Cincinnati, OH, May 16 - 19, 2010.

4. A. A. Mostafa, \& S. E. Elghobashi, Two-Equation Turbulence Model for Jet Flows Laden With Vaporizing Droplets. International Journal of Multiphase Flow, 11(4), pp. 515-533. 1985.

5. A. A. Mostafa, \& H. C. Mongia, On the Modeling of Turbulent Evaporating Sprays: Eulerian versus Lagrangian Approach. International Journal of Heat and Mass Transfer, 30(12), pp. 2583-2593. 1987.

6. J.C. Beck, \& A.P. Watkins, On the development of a spray model based on drop-size moments. Proc. R. Soc. Lond. A, 459(2034), pp. 1365-1394, 2003.

7. J.C. Beck, \& A.P. Watkins, The simulation of fuel sprays using the moments of the drop number size distribution. International Journal of Engine Research, 5(1), pp. 1-21, 2004.

8. B. Yue, \& A. P. Watkins, Mathematical Development and Numerical Analysis of Further Transport Equations for the Droplet Size Moment Theory. 19th Annual Meeting of the Institute for Liquid Atomization and Spraying Systems (Europe). Nottingham, UK, 6- 9 September 2004.

9. N.G. Emekwuru, \& A. P. Watkins, Analysis of a two-fluid sprayer and its use to develop the number size distribution moments spray model, Part II: Computational Analysis, Atomization and Sprays, 20(8), pp. 653-672, 2010.

10. N.G. Emekwuru, Statistical Experimental Analysis of a Two-Fluid Sprayer and its use to develop the Number Size Distribution Moments Model of Sprays, PhD Thesis, University of Manchester, Manchester. 2007. 
11. N.G. Emekwuru, \& A. P. Watkins, Analysis of a two-fluid sprayer and its use to develop the number size distribution moments spray model, Part I: Experimental Analysis, Atomization and Sprays, 20(6), pp. 467-484, 2010.

12. P. Rosin, \& E. Rammler, The Laws Governing the Fineness of Powdered Coal. Journal of the Institute of Fuel, 7, pp. 29-36, 1933.

13. J.C. Beck, \& A.P. Watkins, The droplet number moments approach to spray modeling: The development of heat and mass transfer sub-models. Int $\mathrm{J}$ of Heat and Fluid Flow, 24(2), pp. 242-259, 2003.

14. B. E. Launder, \& D. B. Spalding, Mathematical Models of Turbulence. London: Academic Press, 1972.

15. H.K. Versteeg, \& W. Malalasekera, An Introduction to Computational Fluid Dynamics. The Finite Volume Method, Harlow: Longman Scientific \& Technical, 1995.

16. H. Hiroyasu, \& T. Kadota, Fuel Droplet Size Distribution in Diesel Combustion Chamber. SAE Paper 740715. 1974.

17. R. D. Reitz, \& R. Diwakar, Structure Of High-Pressure Fuel Sprays. SAE Paper 870598. 1987.
18. J.C. Beck, \& A.P. Watkins, On the development of spray submodels based on droplet size moments. J. Computational Physics, 182(2), pp. 586-621, 2002.

19. W. Brandstätter, F. Landertshamer, K. Pachler, Recent Findings Regarding High Pressure Diesel Spray Simulations. ILASS-Europe 14thAnnual Conference on Liquid Atomization and Spray Systems (Europe), Manchester, UK. 6-8 July, 1998.

20. Stekol"shchikov, E.V., Anisimova, M. P., Yatcheni, I .A., Kondrat"ev, O. L. Experimental study concerning the motion and the fragmentation of liquid droplets in a gas stream. $J$ of Eng. Physics and Thermophysics. 23(2), pp. 957-962. 1972.

21. T.-W. Kuo, \& F.V. Bracco, Computations of Drop Sizes in Pulsating Sprays and of Liquid Core Length in Vaporizing Sprays. SAE Paper 820133. 1982.

22. B. Yue, Mathematical Development and Numerical Analysis of Further Transport Equations for the Droplet Size Moment Theory, MPhil Thesis, University of Manchester, Manchester. 2005.

\section{CONTACT}

Dr. Nwabueze G. Emekwuru. MSAE.

Midlands Simulation Group, University of Wolverhampton, UK.

n.emekwuru@wlv.ac.uk.

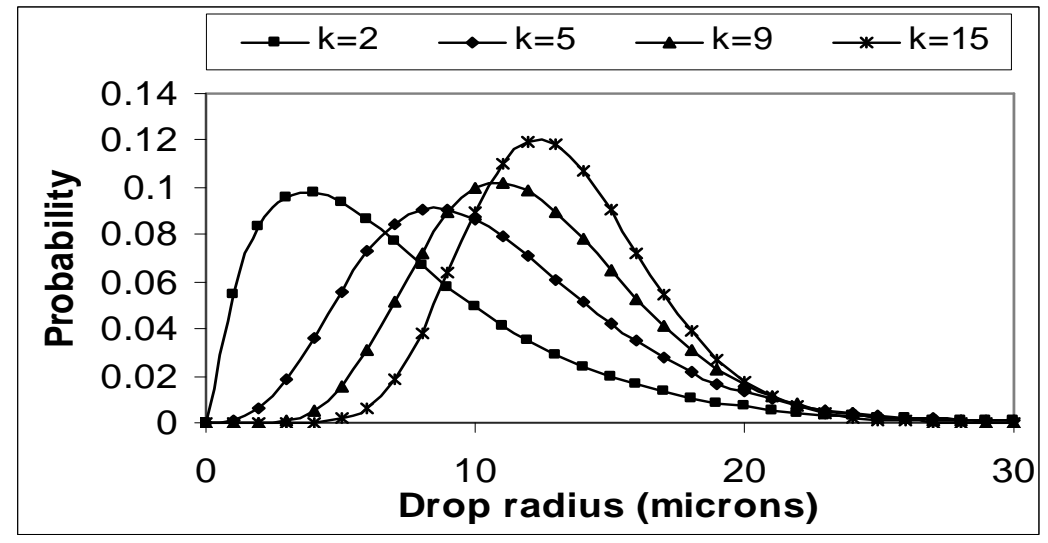

Figure 1: Gamma distributions with $r_{32}=15 \mu \mathrm{m}$ 


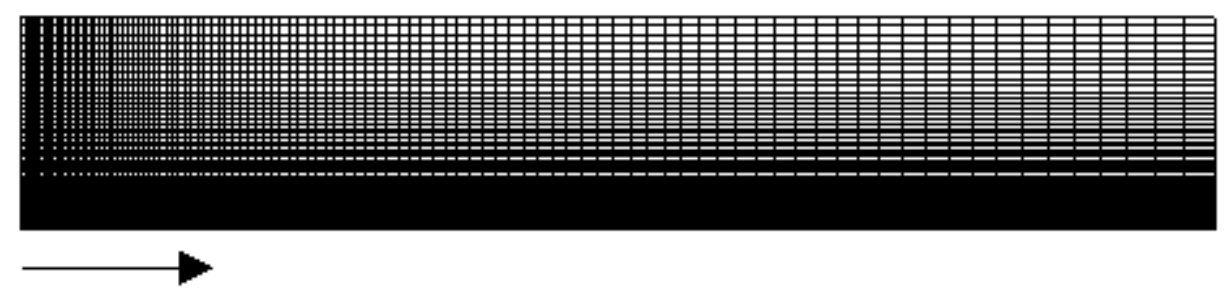

Figure 2: Grid used for the $3 \mathrm{M}$ model with $109 \times 73$ cells. The injector is located on the bottom left hand side, and sprays across the centerline to the right.

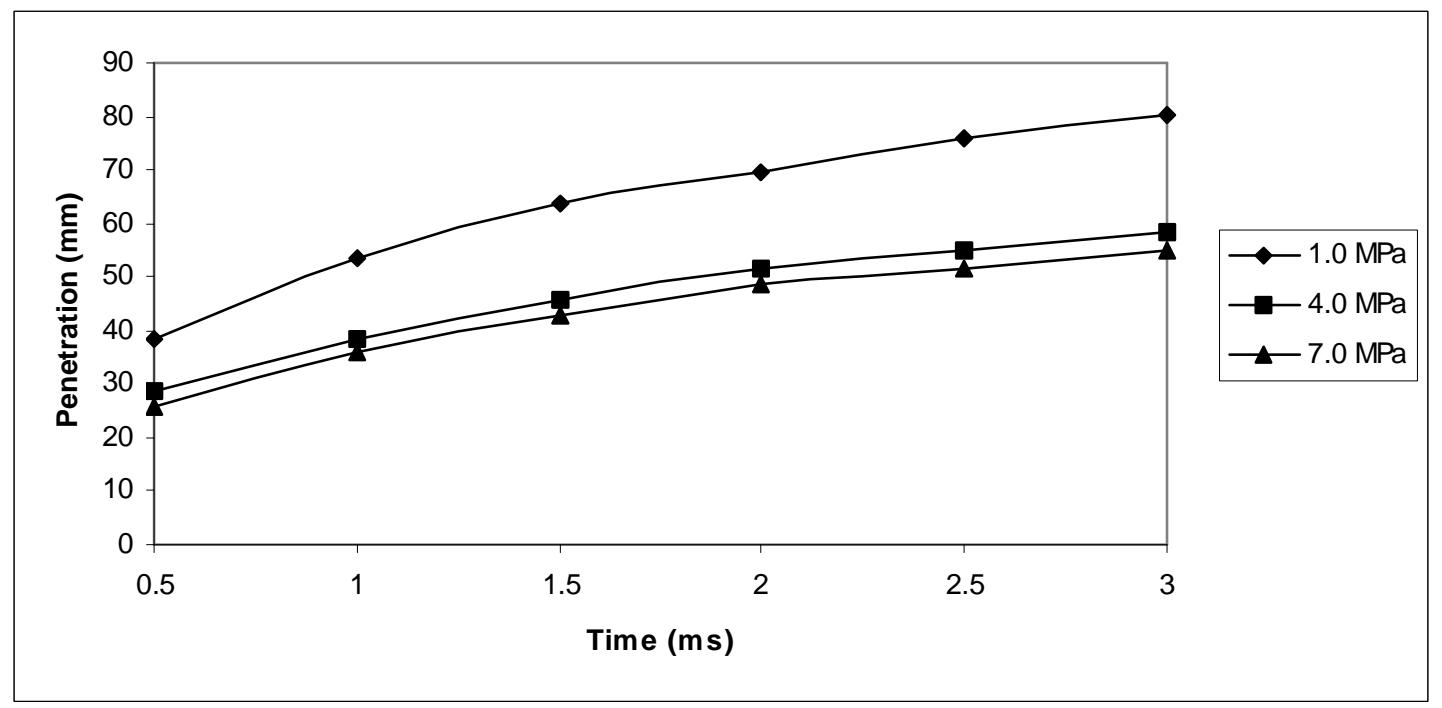

Figure 3: Variation in spray penetration with ambient pressure.

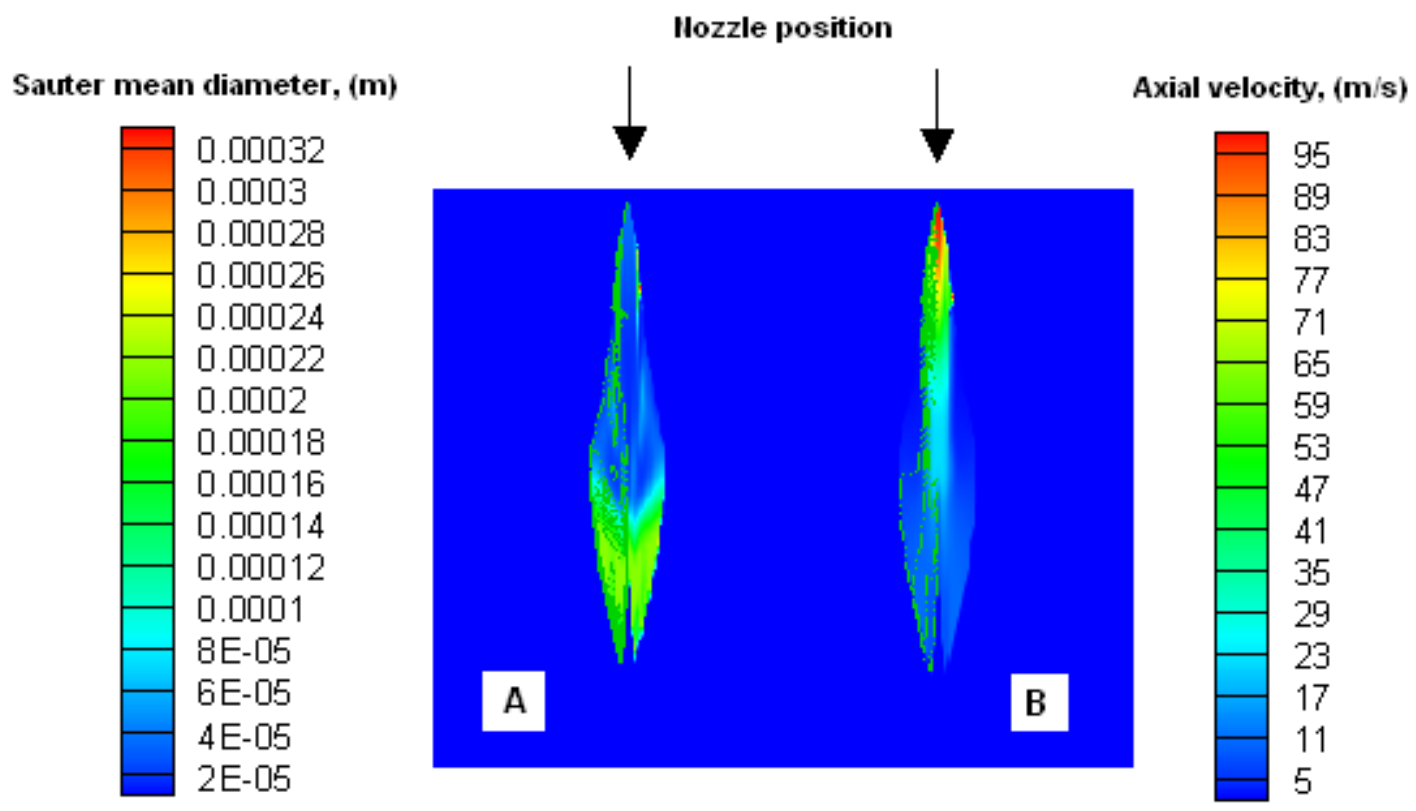

Figure 4: Predicted spray shape contours for the SMD (A), axial droplet velocity (B), at 20ms, 1.1 MPa ambient pressure. The left hand sides of both spray shapes include the flood and line contours, while the right hand sides of the spray shapes show only the flood contours. 


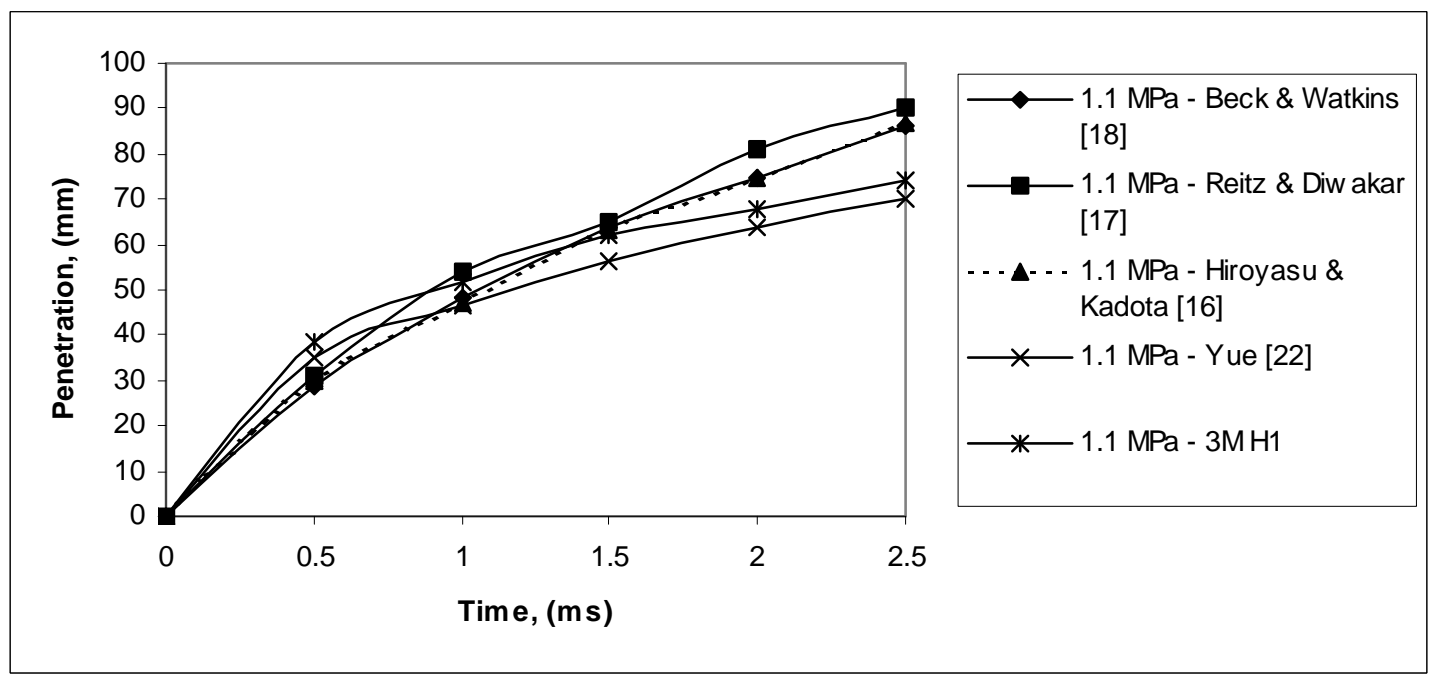

Figure 5: Spray penetration results for the experimental H1 case from Hiroyasu and Kadota [16].

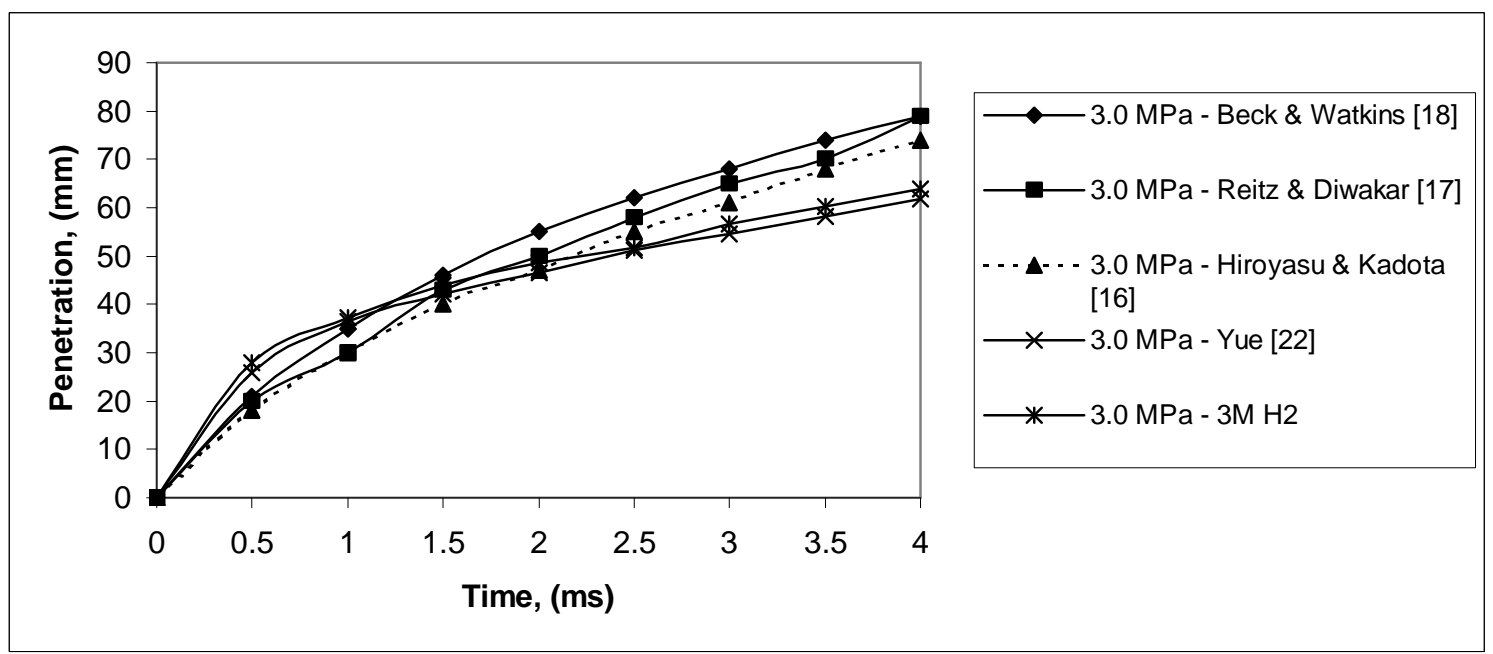

Figure 6: Spray penetration results for the experimental H2 case from Hiroyasu and Kadota [16].

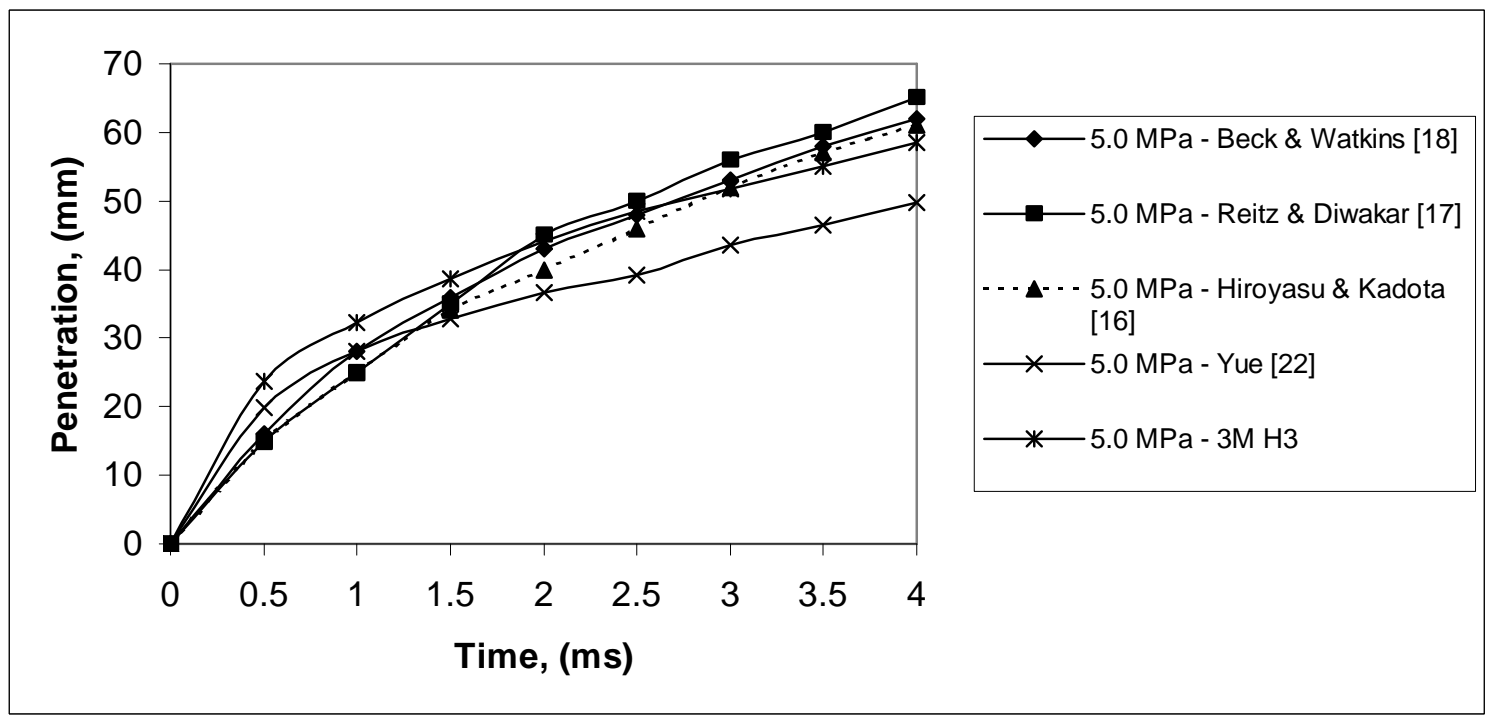

Figure 7: Spray penetration results for the experimental H3 case from Hiroyasu and Kadota [16]. 


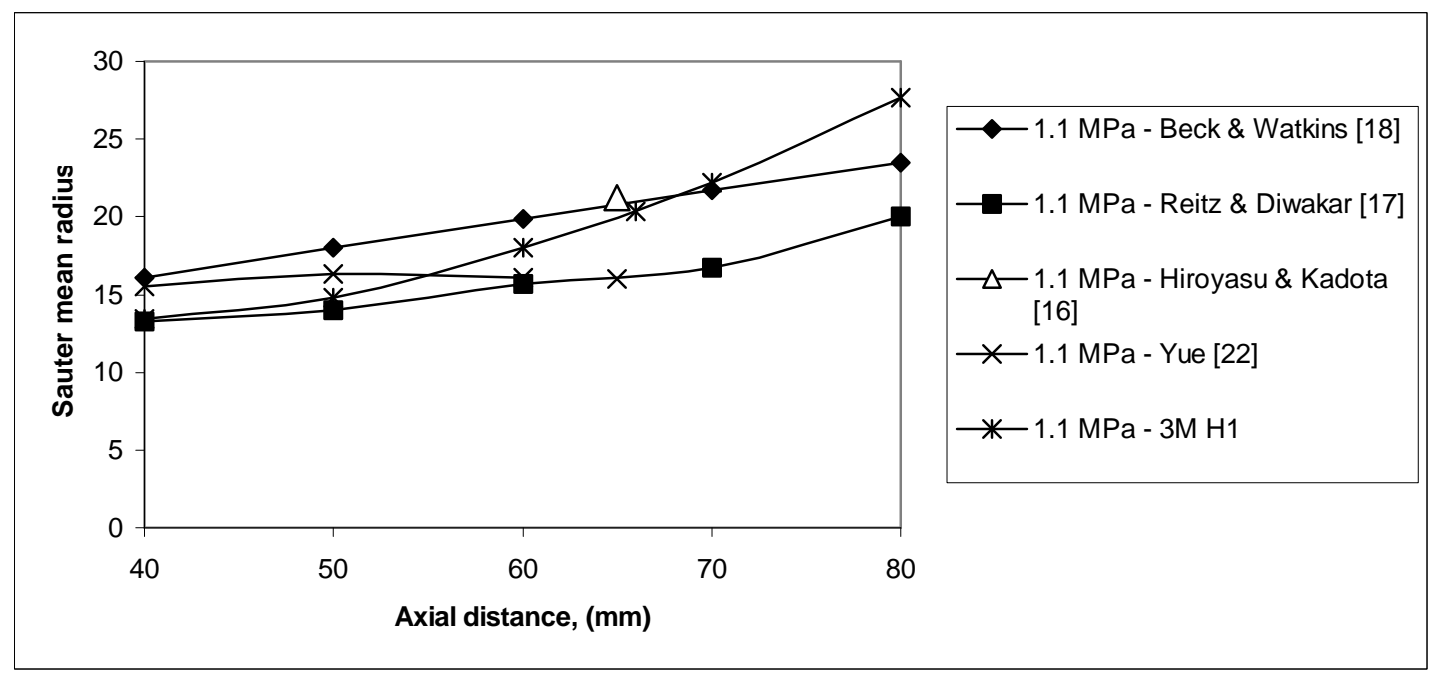

Figure 8: Sauter mean radius results for the experimental H1 case from Hiroyasu and Kadota [16].

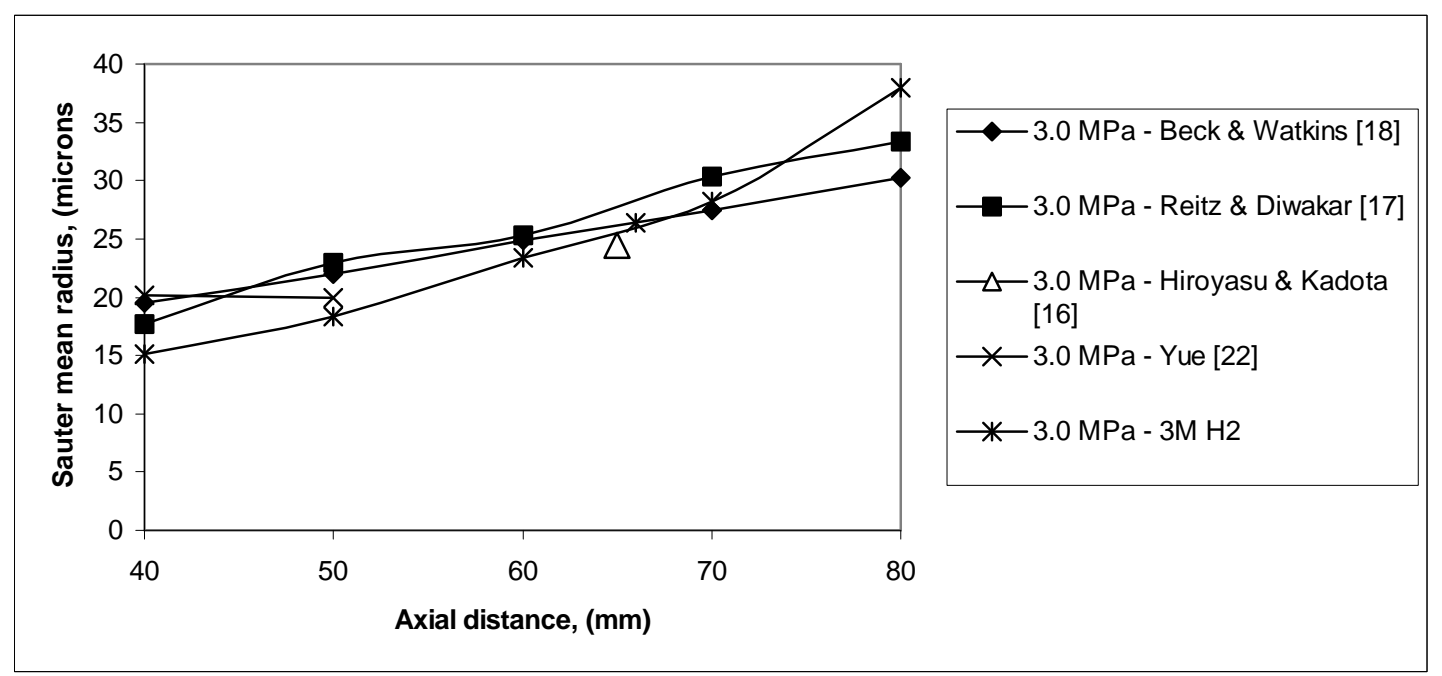

Figure 9: Sauter mean radius results for the experimental H2 case from Hiroyasu and Kadota [16].

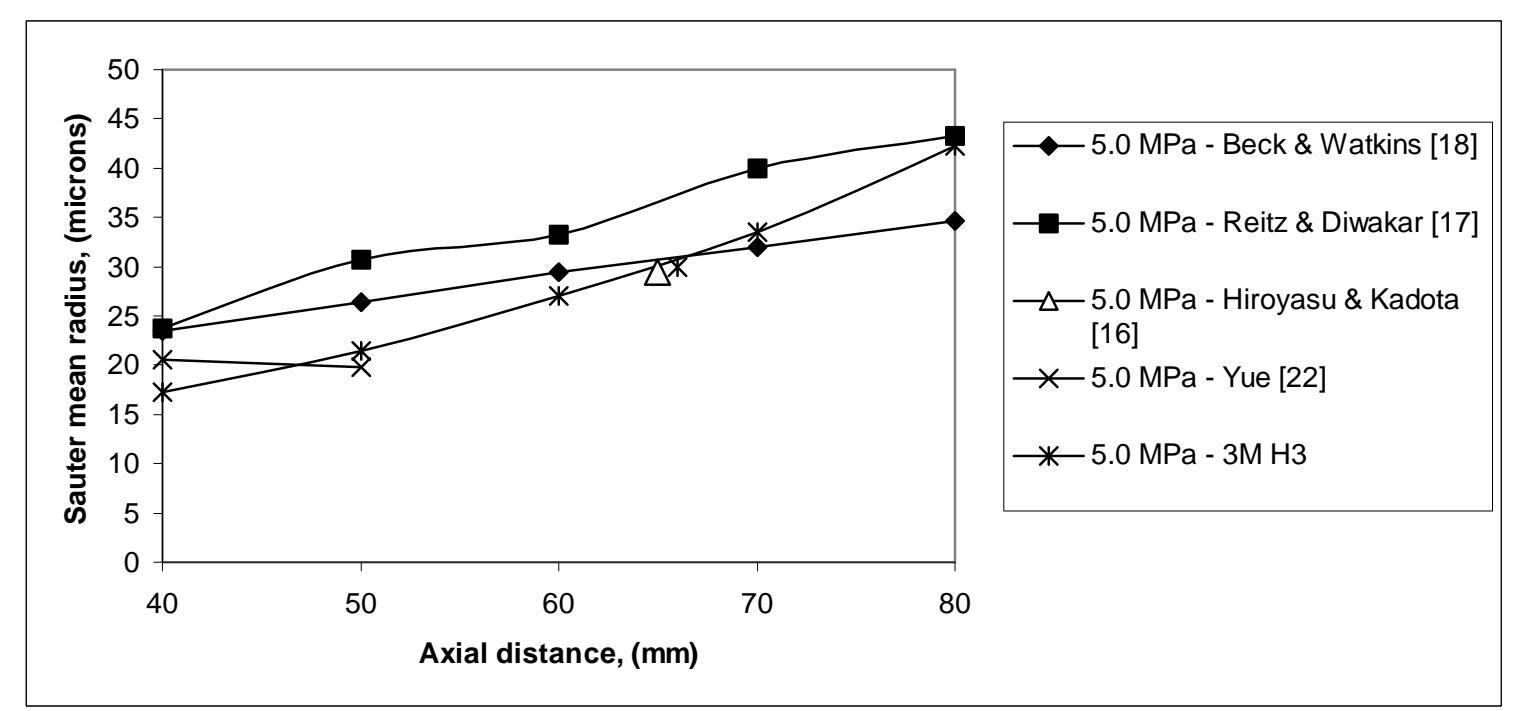

Figure 10: Sauter mean radius results for the experimental H3 case from Hiroyasu and Kadota [16]. 
Table 1: Experimental conditions for the data of Hiroyasu and Kadota [16]

\begin{tabular}{|l|c|c|c|}
\hline & Case H1 & Case H2 & Case H3 \\
\hline Ambient Pressure $(\mathrm{MPa})$ & 1.1 & 3.0 & 5.0 \\
\hline Spray Angle & $10^{\circ}$ & $16^{\circ}$ & $21^{\circ}$ \\
\hline Injection Velocity $\left(\mathrm{ms}^{-1}\right)$ & 102.0 & 90.3 & 86.4 \\
& & & \\
\hline Drop SMR at $65 \mathrm{~mm}(\mu \mathrm{m})$ & 21.2 & 24.5 & 29.4 \\
\hline Injection Pressure $(\mathrm{MPa})$ & 9.9 & 9.9 & 9.9 \\
\hline Nozzle Radius $(\mathrm{mm})$ & 0.15 & 0.15 & 0.15 \\
\hline Density of liquid $\left(\mathrm{kgm}^{-3}\right)$ & 840 & 840 & 840 \\
\hline
\end{tabular}

Table 2: Numerical, physical and injection parameters used for model $3 \mathrm{M}$ to simulate the experiments of Hiroyasu and Kadota [16].

\begin{tabular}{|c|c|c|c|c|}
\hline & & 3M H1 & 3M H2 & 3M H3 \\
\hline 1. & Air atomizing pressure, $(\mathrm{MPa})$ & 9.9 & 9.9 & 9.9 \\
\hline 2. & Ambient pressure, $(\mathrm{MPa})$ & 1.1 & 3.0 & 5.0 \\
\hline 3. & Chamber radius, $\quad(\mathrm{m})$ & \multicolumn{3}{|c|}{0.037} \\
\hline 4. & Chamber, axial length, (m) & \multicolumn{3}{|c|}{0.200} \\
\hline 6. & Injection velocity, $(\mathrm{m} / \mathrm{s})$ & 102.0 & 90.3 & 86.4 \\
\hline 7. & Injector nozzle radius, $(\mathrm{m})$ & \multicolumn{3}{|c|}{0.00015} \\
\hline 8. & Inlet drop SMR, $(\mu m)$, & 21.48 & 21.48 & 21.48 \\
\hline 9. & Number of cells in axial direction & \multicolumn{3}{|c|}{109} \\
\hline 10. & Number of cells in radial direction & \multicolumn{3}{|c|}{73} \\
\hline 11. & Spray cone angle, (degrees) & 10 & 16 & 21 \\
\hline 12. & Gamma size distribution parameter, $k$ & \multicolumn{3}{|c|}{3.5} \\
\hline 13. & Computational Time step, $(\mu s)$ & \multicolumn{3}{|c|}{5.0} \\
\hline 14. & Total computation time, $(\mathrm{ms})$ & \multicolumn{3}{|c|}{20} \\
\hline
\end{tabular}


Table 3: Numerical, physical and injection parameters used by Beck \& Watkins [18] and Yue [22] to simulate the experiments of Hiroyasu and Kadota [16].

\begin{tabular}{|c|c|c|c|c|}
\hline & & $\begin{array}{c}\text { Yue } \\
\text { [22]/Beck \& } \\
\text { Watkins[18] } \\
\text { H1 }\end{array}$ & $\begin{array}{c}\text { Yue } \\
\text { [22]/Beck \& } \\
\text { Watkins[18] } \\
\text { H2 }\end{array}$ & $\begin{array}{c}\text { Yue } \\
\text { [22]/Beck \& } \\
\text { Watkins[18] } \\
\text { H3 }\end{array}$ \\
\hline 1. & Air atomizing pressure, $(\mathrm{MPa})$ & 9.9 & 9.9 & 9.9 \\
\hline 2. & Ambient pressure, $(\mathrm{MPa})$ & 1.1 & 3.0 & 5.0 \\
\hline 3. & Chamber radius, $\quad(\mathrm{m})$ & \multicolumn{3}{|c|}{0.037} \\
\hline 4. & Chamber, axial length, (m) & \multicolumn{3}{|c|}{0.200} \\
\hline 6. & Injection velocity, $(\mathrm{m} / \mathrm{s})$. & 101.78 & 90.13 & 75.95 \\
\hline 7. & Injector nozzle radius, $(\mathrm{m})$ & \multicolumn{3}{|c|}{0.00015} \\
\hline 8. & Inlet drop SMR, $(\mu m)$. & $\begin{array}{l}15[18] \\
20[22]\end{array}$ & 20 & 20 \\
\hline 9. & Number of cells in axial direction & \multicolumn{3}{|c|}{109} \\
\hline 10. & Number of cells in radial direction & \multicolumn{3}{|c|}{73} \\
\hline 11. & Spray cone angle, (degrees). & 9.91 & 16.3 & 20.95 \\
\hline 12. & $\begin{array}{l}\text { Gamma size } \\
\text { parameter, } k\end{array}$ & \multicolumn{3}{|c|}{$3.5[22]$} \\
\hline 13. & Computational Time step, $(\mu s)$ & 2 & 2.5 & 2.5 \\
\hline 14. & Total computation time, $(\mathrm{ms})$ & 12 [18] & $15[18]$ & $25[18]$ \\
\hline
\end{tabular}

